\title{
O DOCEnTE E SUA CONSTANTE RECONSTRUÇÃo DE SABERES: O JOGO COMO FERRAMENTA DE RESSIGNIFICAÇÃO DE SUA PRÁTICA
}

\author{
THE TEACHER AND HIS CONSTANT RECONSTRUCTION OF \\ KNOWLEDGE:THE GAME AS A TOOL OF RESIGNIFICATION OF YOUR \\ PRACTICE
}

DOI: http://dx.doi.org/10.23926/RPD.2526-2149.2020.v5.n1.p289-305.id608

\section{Diogo da Silva \\ Doutorando em Ensino de Ciências e Educação \\ Matemática (UEL) \\ Professor da secretária de educação do estado do \\ Paraná \\ diogo-bio@hotmail.com}

Álvaro Lorencini
Junior
Doutorado em Educação,
área de Didática pela
Faculdade de Educação da
USP (FEUSP)
Docente do Programa de
Pós-graduação em Ensino de
Ciências e Educação
Matemática (UEL)
alvarojr@uel.br

Resumo: Este artigo tem como objetivo relatar uma experiência de atividade interativa envolvendo um jogo didático sobre alimentos com os alunos do Ensino Médio nas aulas de Biologia de uma escola do município de Rolândia/PR em que se aplicou primeiramente um questionário investigando os modos alimentares e a frequência de atividades físicas. Os resultados obtidos foram discutidos à luz do envolvimento dos alunos neste jogo interativo e dos referenciais de formação de professores que indicaram que a participação expressiva dos alunos fez com que o professor refletisse sobre a sua prática numa relação em que o aperfeiçoamento do ensino do professor dependeu da efetiva aprendizagem dos alunos.

Palavras-chave: Formação Docente, Saberes Docentes, Jogo Didático..

\begin{abstract}
This article aims to report an interactive activity experience involving a didactic game about food with high school students in the Biology classes of a school at city Rolândia / PR in which a questionnaire was first applied to investigate dietary modes and frequency physical activities. The results obtained were discussed in the light of the students' involvement in this interactive game and the teacher training references that indicated that the expressive participation of the students made the teacher reflect on his practice in a relationship in which the improvement of the teacher's teaching depended effective student learning.
\end{abstract}

Keywords: Teacher Education, Teaching Knowledge, Didactic Game. 


\title{
1 FormaÇÃO DOCENTE
}

A formação do profissional professor vem sendo esboçada durante sua trajetória acadêmica como aluno e como docente. Essa personificação do professor encontra-se muito arraigada, expressando práticas e ações as quais o mesmo participou durante a vida escolar e acadêmica, sendo estas referências de como mediar e construir o conhecimento. Essas referências de concepção do conhecimento transparecendo uma forte resistência à mudança, logo é fundamental um conflito que possa transformar seu modelo didático pessoal em relação ao seu trabalho, considerando a integração dos conhecimentos diversos que lhes são garantidos durante sua formação docente, bem como reconhecendo seus limites, barreiras e entrelaçamentos interdisciplinares (FÚRIO et al., 1992, p. 19) discute:

\begin{abstract}
Assim, o objecto de métodos de ensino específicos pode proporcionar não só a estruturação do conhecimento (educação, psico-socio-educacional e científico), mas também a sua integração com a prática de ensino, favorecendo a sua orientação teórica, orientando atividades educacionais e promover reflexão crítica após a interação.
\end{abstract}

Os saberes componentes do conhecimento profissional dos docentes encontram-se entrelaçados de tal maneira que não se pode colocá-los separados ou sozinhos. Reconhecemos assim que tais conhecimentos teóricos (psicológico, disciplinar, curricular, pedagógico, sócio histórico e metodológico) permaneceriam associados durante a formação prática do professor (Furió; Gil-Pérez, 1989).

As pesquisas de Stenhouse (1987) e Pérez-Gómez (1998) apresentam um ponto de vista em relação ao currículo e a valorização dos docentes, que como agentes ativos constroem o currículo, justificando o currículo como uma representação da cultura escolar envolvendo as relações entre teoria e prática, bem como entre educação e sociedade:

[...] a formação deve estimular uma perspectiva crítico-reflexiva, que forneça aos professores os meios de um pensamento autônomo e que facilite as dinâmicas de autoformação participada. Estar em formação implica um investimento pessoal, um trabalho livre e criativo sobre os percursos e os projectos próprios, com vistas à construção de uma identidade, que é também uma identidade profissional (NÓVOA, 1991, p. 25)

Sendo assim, o professor coloca em prática todos os seus saberes, experiências como aluno e como professor, estabelecendo conexões entre o que aprendeu e como aprendeu em o que ensina e da forma com o qual ensina uma relação reflexiva sistematizada para um público heterogêneo e carregada de valores próprios. O professor atuante em sala de aula concebe reconstrução constante de seu conhecimento sobre como ensinar por meio de suas próprias 
práticas. É preciso reconhecer o professor como investigador, refletindo antes durante e depois de sua prática, adequando o currículo a realidade discente (FILHO, 1987).

Os avanços da Ciência, das tecnologias e da sociedade nos fazem cotidianamente repensar ações pedagógicas muitas vezes no âmbito social e ético. A renovação contínua de materiais produzidos pela área científica nos faz refletir sobre novos posicionamentos por meio da docência em relação ao como abordar esses assuntos com os discentes.

\section{CENÁRIO ESCOLAR CONTEMPORÂNEO}

Atualmente o cenário escolar vem sendo repensado diante das abordagens didáticas e metodológicas utilizadas, em função da progressão da sociedade contemporânea e a necessidade de uma renovação e adequação de instrumentos, didáticas e práticas norteadoras do processo ensino e aprendizagem. Os professores do ensino básico se veem atualmente diante de uma constante renovação dos conteúdos, assuntos e temáticas que norteiam à ciência como disciplina escolar e os recursos e instrumentos na qual os mesmos são mediados pelos docentes.

Sobre o cenário contemporâneo, Batista e Salvi (2006) considera:

Um dos aspectos mais interessantes nesse novo período é a aceitação de que teorias, conceitos, modelos e soluções anteriormente considerados suficientes na resolução de problemas científicos e sociais passam por um crivo crítico e se dão como alvo de questionamentos, o que nos leva a pensar que o que está realmente em crise é o modelo de civilização no seu todo, ou seja, o paradigma da Modernidade. (BATISTA e SALVI, 2006, p. 148)

Logo, os processos de ensinar e aprender requer se não novas habilidades e competências, ao menos a consciência de que, acima de tudo atualmente, vivemos em um período em que conhecimentos científicos, sociológicos e técnicos se mostram conectados, comunicando-se em um meio sistemático e organizado (BATISTA; SALVI, 2006).

Em se tratando da formação de professores em serviço parece que a desatualização dos professores referente às novas práticas didáticas que ocorrem por inúmeros motivos, e que se faz necessário inovar com novas didáticas e metodologias para tornar significativo o processo de ensino e aprendizagem.

De acordo com Martins (2008) em relação ao letramento científico:

“[...] uma caracterização do fenômeno do letramento para além de concepções reducionistas, que restringem a aprendizagem da leitura e da escrita à competência na codificação e decodificação de informação, para uma concepção na qual esta aprendizagem importa na medida que permite tomar parte em situações sociais as quais o conhecimento científico toma parte. (MARTINS, 2008, p. 09) 
Os conceitos de Ensino e Aprendizagem e o papel dos docentes devem ser revistos à medida que concebemos que o aprendiz, seja ele quem for, é o artesão de seu próprio conhecimento, amparado ou não pela escola.

Sob tal ponto de vista, o professor além de responsável pelo ensino, também tem como obrigação compreender os mecanismos do conhecimento frente ao processo aprendizagem. Esses mecanismos da construção do conhecimento estão relacionados com o reconhecimento de como instruir, abordar, aplicar e contextualizar tais saberes. Compreendendo que os saberes docentes estão subordinados ao conhecimento prático e conhecimento didático. Assim, em função da progressão da sociedade contemporânea e a necessidade de uma renovação e adequação de instrumentos, práticas e abordagens norteadoras do processo ensino e aprendizagem.

\title{
2.1. NOVAS PRÁTICAS PARA NOVOS CENÁRIOS
}

Para Felix e Navarro (2009):

\begin{abstract}
As mudanças atuais no conceito do que é ensinar diz respeito à capacidade de ir além dos conteúdos e das informações didáticas, de modo que estes possibilitem a aprendizagem como uma competência central que possa ser desenvolvida tanto pelo educador quanto pelo educando, através de suas próprias realidades vividas. Tal ideia vem superar o conceito de ensino enquanto informação, apoiado numa relação passiva professor-aluno, que na maioria das vezes, por meio do livro didático, transmite as informações para o aluno, que normalmente as repetem, sem conseguir associá-las a uma interpretação e ligação com a realidade, que forneça sentido ao próprio aprendizado. (FELIX; NAVARRO, 2009, p. 02)
\end{abstract}

Em relação ao papel do professor, para Del Prette et al (1996), enquanto sujeito participante dos processos educativos, o mesmo conduz e faz a mediação das interações educativas, além da competência profissional, é de extrema importância um repertório suficientemente diferenciado das habilidades sócio cognitivas, tais como planejar, avaliar e fornecer feedback, planejamento e coordenação de atividades de grupo, se apresentar flexível para mudanças na atuação em sua prática, na percepção das demandas imediatas do contexto escolar, entre outros aspectos que são inerentes à formação do profissional docente contemporâneo, que está centrado nas relações interpessoais. Ainda referente a competências e habilidades, Felix e Navarro (2009) apresentam,

\footnotetext{
Algumas competências e habilidades que não podem deixar de existir no trabalho em sala de aula são: respeitar as identidades e as diferenças; utilizar-se das linguagens como meio de expressão, desenvolver a comunicação e a apreensão de informações; inter-relacionar pensamentos, ideias e conceitos; desenvolver o pensamento crítico e flexível e a autonomia intelectual; adquirir, avaliar e transmitir informações; compreender os princípios das tecnologias e suas relações integradoras; entender e ampliar fundamentos científicos e tecnológicos; desenvolver a criatividade; saber conviver em grupo e aprender a aprender. (FELIX; NAVARRO, 2009, p. 03)
} 
É fundamental admitir a recorrente construção da prática docente por meio da tomada de decisões, aplicadas em situações únicas e particulares em um contexto escolar plural e heterogêneo, tal constatação possibilita a ressignificação permanente de um corpo de conhecimentos, habilidades e instrumentos que são mobilizados a todo tempo, se adequando aos objetivos educativos esperados e ao público alvo que se deseja sensibilizar, evidenciando a autonomia do profissional professor. Sendo assim, como recurso pedagógico e meio de investigação para esta pesquisa, foi elaborado um jogo na tentativa de aproximação dos alunos e docente e assim tornar o processo de ensino e aprendizagem mais interativos.

Esta prática foi uma tentativa de superar a ação tradicional constante no cenário escolar, a qual torna a rotina de sala de aula menos produtiva e integradora, a qual restringe o educando no papel de ouvinte, passivo e executar de tarefas ordenadas (ROSSANI, 2007).

Teve-se como objetivo deste trabalho, refletir a respeito da construção dos saberes docentes que são re-significados com a prática, por meio da investigação de um problema social relatado pelos alunos participantes envolvidos, "hábitos alimentares e atividade física", e assim a produção de um instrumento pedagógico o jogo NutriBank, com isso reconhecendo a eficácia do recurso didático produzido e as percepções do professor diante da construção de novas práticas.

\subsection{O Jogo DidÁtico COMO InSTRUMENTO INTERATIVO PARA A APRENDIZAGEM.}

Durante as movimentações do jogo, a espontaneidade é estimulada o que causa motivação suficiente para que o participante ultrapasse a si mesmo. Segundo Miranda (2002), a utilização de jogos em sala de aula pode trazer benefícios pedagógicos a fenômenos diretamente ligados à aprendizagem: cognição, afeição, socialização, motivação e criatividade.

Ele é mobilizado para adentrar no ambiente, explorar, aventurar-se e enfrentar desafios, o que favorece a autoestima do indivíduo e a sua interação com o mundo em que está inserido. Com as interações pelos jogos a criança desenvolve ações, tem sua curiosidade estimulada e exercita sua autonomia e motricidade (VYGOTSKY, 1984; FREIRE, 1989)

Para Vygotsky (1984), o uso dos jogos proporciona ambientes desafiadores, capazes de "estimular o intelecto" proporcionando a conquista de estágios mais avançados de raciocínio. Quando o professor propõe situações de jogos na sala de aula, ocasiona momentos de afetividade entre a criança e o aprender, tornando a aprendizagem mais significativa e prazerosa. 
Perante o apresentado, buscou-se um instrumento didático que potencializasse o processo de aprendizagem e o desenvolvimento do espírito de construção de conhecimento por meio da interação entre o estudante e o jogo.

As hipóteses que orientaram a pesquisa foram:

- As situações apresentadas no jogo NutriBanck demandam o uso de competências e habilidades cognitivas, estas como: elaborar propostas para intervenção na realidade, solucionar problemas, tomar decisões, compreender fenômenos e associação de conceitos.

- A criação de estratégias para solução de problemas é potencializada pelo jogo NutriBanck.

\subsection{TEMÁtiCA DO JOGO}

A obesidade é considerada uma epidemia mundial independente de condições econômicas e sociais. Ela aumenta o risco de mortalidade, já que proporciona um ambiente favorável para doenças como hipertensão, diabetes e problemas circulatórios.

No Brasil, as mudanças demográficas sociais, econômicas e epidemiológicas ao longo do tempo permitiram a denominada transição nos padrões nutricionais, com a diminuição progressiva da desnutrição e o aumento da obesidade (GOMES; FILHO, 1992).

Isso se torna um problema social de saúde pública, já que as consequências da obesidade para a saúde são muitas e potencializam o risco de morte prematura e doenças ligadas ao sedentarismo que afetam a qualidade de vida destes indivíduos.

A partir da década de 1980 quando a medicina deu ênfase referente aos riscos em que a inatividade física pode provocar no ser humano, os profissionais de educação física buscaram se aprofundar nos conhecimentos relacionados a esta problemática, para então, desenvolver e elaborar atividades que visassem principalmente a prevenção ou a melhora nos aspectos da saúde (GOMES; FILHO, 1992).

Saúde e qualidade de vida estão de tal forma interligadas que na realidade é muito difícil separá-las tanto na prática como na elaboração de um programa que tenha esses itens como finalidade (GUISELINI, 2004).

Buscar a interação do conceitual científico, sua relação com o senso comum e torná-lo significativo também é um papel do educador. Em discussões sobre o processo de aprendizagem, pontua-se a aprendizagem significativa, definindo-a como um processo de 
interação de novas ideias com conceitos relevantes presente na estrutura cognitiva do aprendiz (MOREIRA, 2009).

\section{Procedimentos Metodológicos}

\subsection{Pesquisa e Produção do Jogo}

Os temas, "saúde, alimentação e atividade física" eram alvos de discussão durante as aulas de Biologia. Logo, tal contexto proporcionou a inspiração de desenvolver e aplicar um jogo que abordasse tais conceitos e comportamentos. Com isso, foi realizada uma pesquisa de campo envolvendo 100 (cem) alunos do Ensino Médio de um colégio particular, na cidade de Rolândia, região norte do Paraná, onde por meio de um questionário, buscou-se conhecer o perfil dos sujeitos em relação à problemática de alimentação e seu grau de sedentarismo. Assim os procedimentos de elaboração do jogo e aplicação do mesmo foram divididos em 3 etapas.

\subsubsection{1 ${ }^{a}$ ETAPA: ELABORAÇÃO DE QUESTÕES MAIS APROFUNDADAS REFERENTE A} ALIMENTAÇÃo

Uma equipe de 12 (doze) alunos do primeiro e segundo ano do Ensino Médio ficou responsável por elaborar questões mistas (abertas e fechadas) que investigariam a proporção de alunos que praticam atividades físicas e sua frequência, bem como, se os sujeitos consideravam a sua própria alimentação como saudável, e quantos fazem ingestão de alimentos do tipo fast food, frutas e verduras.

Esta pesquisa abordou tais questões, pois, anteriormente durante as aulas os alunos relataram que ingeriam com frequência alimentos do tipo fast food, e não gostavam de frutas e verduras, nem mesmo reconheceram a importância nutricional de sua ingestão.

\subsubsection{2a ETAPA: COLETA DE DADOS}

A equipe providenciou cédulas com as perguntas elaboradas com respostas "Sim" e "Não" (questões 1, 2 e 3) e perguntas com espaços para respostas descritivas, e espaço para comentários (questões 4 e 5), tais cédulas foram distribuídas para todos os alunos da escola. E continham as seguintes perguntas: 1) Você pratica atividade física superior a 30 minutos? 2) Se sim, qual a frequência? 3) Você considera sua alimentação saudável? E perguntas abertas como, 4) Quantas vezes por semana você ingere fast food? 5) Quantas vezes por semana você ingere frutas e verdura? Comente sobre os alimentos que você ingere com frequência e se não prática atividade física, o porquê. As cédulas foram coletadas e os resultados foram tabulados e 
expostos em forma de histograma (Histograma 5 e 6) e os comentários serão apresentados nos resultados e discussões deste relato de experiência.

\subsubsection{3a Etapa: Pesquisa E CONSTRUÇão de UM InSTRUMENTO didÁtico - Jogo} NUTRIBANK

Após a análise dos dados, a equipe de alunos junto ao professor investigou diversos tipos de jogos e suas construções. Por fim, o jogo do tipo tabuleiro e cartas seria o instrumento didático a ser desenvolvido, e que o mesmo, abordasse as proporções nutricionais dos alimentos interligando com a atividade física em frequência regular, esperando que tal recurso didático proporcionasse a reflexão em aliar bons modos alimentares e adequação de práticas físicas de forma que não se percebesse como uma obrigação, mas sim uma opção.

Em seguida, os alunos esboçaram as primeiras ideias e com os direcionamentos do professor foram surgindo os desenhos e esquemas gráficos, construídos posteriormente em formato digital.

\subsection{JOGO NUTRIBANK}

Após a análise dos dados e a investigação de jogos, a equipe definiu o nome do jogo como NutriBank, sugerindo um banco nutricional, bem como a produção de suas regras, instruções e cartas que o compõe. Regras e instruções do jogo serão apresentadas a seguir no Quadro 1 e na sequência seus componentes. O jogo foi elaborado para ser praticado com alunos durante aulas, oficinas ou eventos que tivesse como objetivo a discussão e reflexão de equilibrar a ingestão e gasto calórico dos alimentos.

Quadro 1 - Regras e Instruções do Jogo NutriBank

\section{REGRAS NUTRIBANK}

Este jogo tem por objetivo equilibrar a ingestão calórica e o gasto calórico da família.

$\mathrm{N}^{\circ}$ de participantes: 2 a 6 pessoas

Componentes:

- 1 Tabuleiro

- 120 Cartas de alimentos

- 66 Cartas de exercícios

- 1 Quadro devedor

- 1 Calculadora

- Moedas:
- 50 cartas de $1 \mathrm{Kcal}$
- 50 cartas de 5 Kcal
- 35 cartas de 20 Kcal
- 60 cartas de 50 Kcal
- 30 cartas de $100 \mathrm{kcal}$ 


\section{○ 30 cartas de $200 \mathrm{Kcal}$}

Cada jogador retira do banco 2000 moedas, em seguida retira as cartas dos alimentos correspondentes às refeições do dia, já feitas ou que ainda o serão. O jogador deve fazer os cálculos das Kcal de suas refeições (pode utilizar à calculadora); ele deve pagar (devolver ao banco) o valor correspondente à soma dos alimentos escolhidos. O ideal é que os Kcal dos alimentos ingeridos no dia todo não ultrapassem $2000 \mathrm{Kcal}$ (Com base na pirâmide alimentar proposta de Walter C. Willett 203); caso isso ocorra, o valor excedente deve ser marcado no quadro devedor; para pagar esta dívida o jogador pode escolher dentre as cartas de exercício a atividade que mais lhe agrada, deverá cumprir o tempo de atividade correspondente à sua dívida em um ou mais aparelhos de academias ao ar livre para que seu saldo (dívida) liquidado possa ser apagado. A escolha das cartas, cálculos de kcal e marcações do saldo devedor devem ser feitas quando o grupo se reunir; os exercícios podem ser feitos individualmente.

Fonte: Autor.

\subsubsection{COMPONENTES DO JOGO NUTRIBANK}

Figura 1 - Tabuleiro montado pela própria equipe

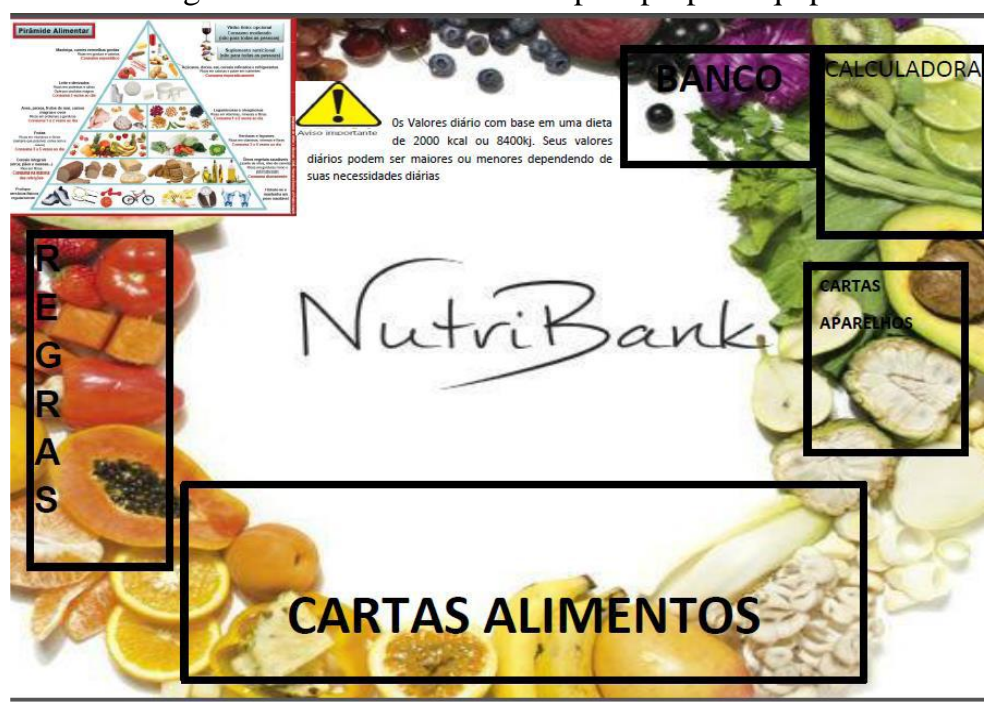

Fonte: Autores

Tabuleiro: 1 Tabuleiro (60x60) $\mathrm{cm}$ de madeira, onde foi colado a Figura 1, impresso no tabuleiro a Pirâmide alimentar $(20 \times 20) \mathrm{cm}$ e espaços demarcados com seus respectivos tamanhos para as cartas dos alimentos, cartas dos aparelhos, regras, banco (moedas) e calculadora. 
Figura 2 - Exemplos de cartas de alimentos

Fast Food (Gorduras)

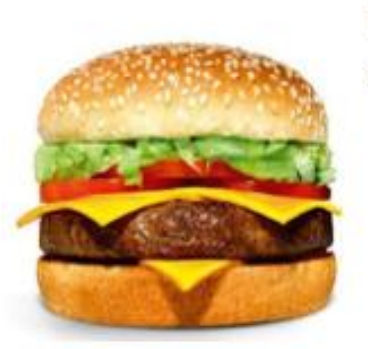

Tabela Calórica

Quantidade por porção: uma unidade

\begin{tabular}{|l|l|l|}
\hline Tipo & Kcal & VD \\
\hline Double Grill Bacon & 1314 & $65,7 \%$ \\
\hline $\begin{array}{l}\text { BK Stacker } \\
\text { Quadruplo }\end{array}$ & 1018 & $50,9 \%$ \\
\hline
\end{tabular}

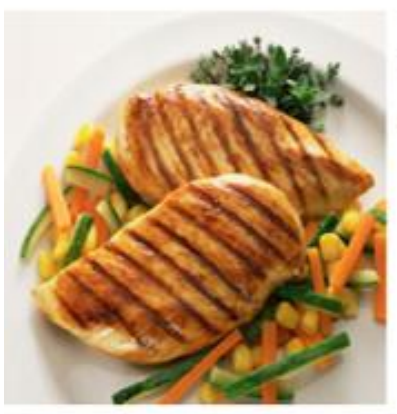

Frango (Carnes)

Tabela Calórica

Quantidade por porção: um pedaço médio

\begin{tabular}{|l|l|l|}
\hline Tipo & Kcal & VD \\
\hline Frito & 224,49 & $11,5 \%$ \\
\hline Assado & 381,6 & $19,08 \%$ \\
\hline Cozido & 163 & $8,15 \%$ \\
\hline Grelhado & 159 & $7,95 \%$ \\
\hline
\end{tabular}

Fonte: Autores.

Cartas alimentos: 6 Cartas de cada alimento, $15 \mathrm{~cm}$ comprimento $\mathrm{x} 7 \mathrm{~cm}$ largura, total de 20 tipos de alimentos. Os alimentos selecionados para a confecção das cartas foram descritos pelos alunos investigados no espaço de comentários do questionário proposto na pesquisa. $\mathrm{Na}$ carta além da imagem do alimento está presente os tipos de preparo do mesmo, bem como os valores de Kcal junto aos valores diários.

Figura 3 - Exemplos de cartas dos aparelhos da academia ao ar livre

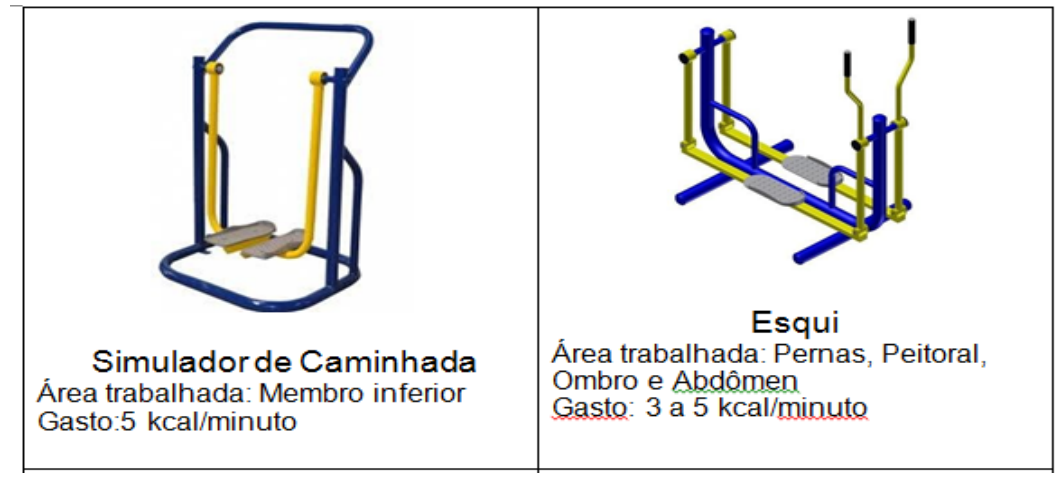

Fonte: Autor.

Cartas aparelhos da academia ao ar livre: 6 Cartas de cada aparelho de academias ao ar livre $7 \mathrm{~cm} \mathrm{x} 7 \mathrm{~cm}$, total de 12 aparelhos. Junto a imagem do aparelho foi impresso a área do corpo trabalhada e o gasto calórico da atividade aliado ao tempo. Os aparelhos selecionados para a produção das cartas são aparelhos da academia ao ar livre situada ao lado da escola.

Cartas moedas: $10 \mathrm{~cm}$ Comprimento x $5 \mathrm{~cm}$ largura 
Figura 4 - Exemplo de carta de moeda

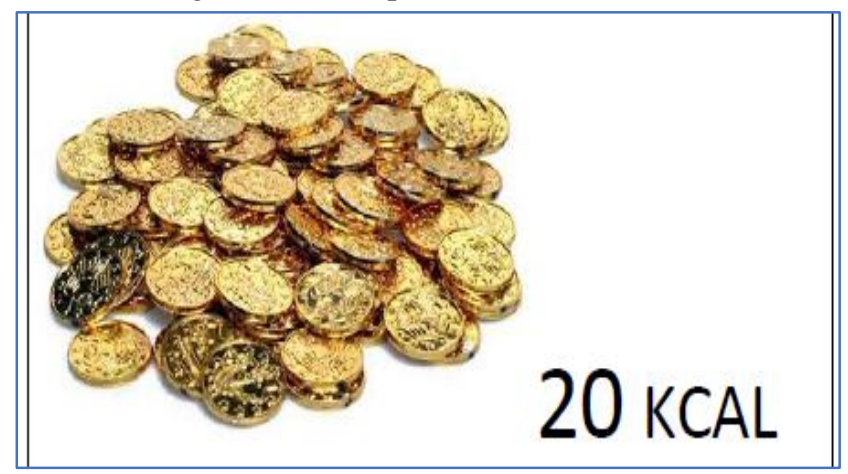

Fonte: Autores

\section{Resultados e Discussões}

Por ser uma investigação qualitativa baseada em Bogdan e Biklen (1994), buscou-se compreender os registros da pesquisa aplicada e dos relatos dos alunos na produção e desenvolvimento e aplicação do Jogo NutriBank.

De acordo com Bardin (2007), existem 3 etapas na organização de uma boa análise de conteúdo, são elas, pré-análise, exploração do material e o tratamento dos resultados. Serão analisadas as respostas dos alunos em relação ao questionário e será exposto relatos dos alunos em relação ao jogo.

Após a coleta dos questionários, evidenciou que $75 \%$ destes alunos não praticavam atividade física com tempo maior de trinta minutos em frequência de três vezes por semana. Em relação à alimentação, 68\% dos alunos responderam não usufruir de uma dieta adequada, rica em frutas e verduras, para manter o peso ideal e assim o não sobrepeso (Figura 5).

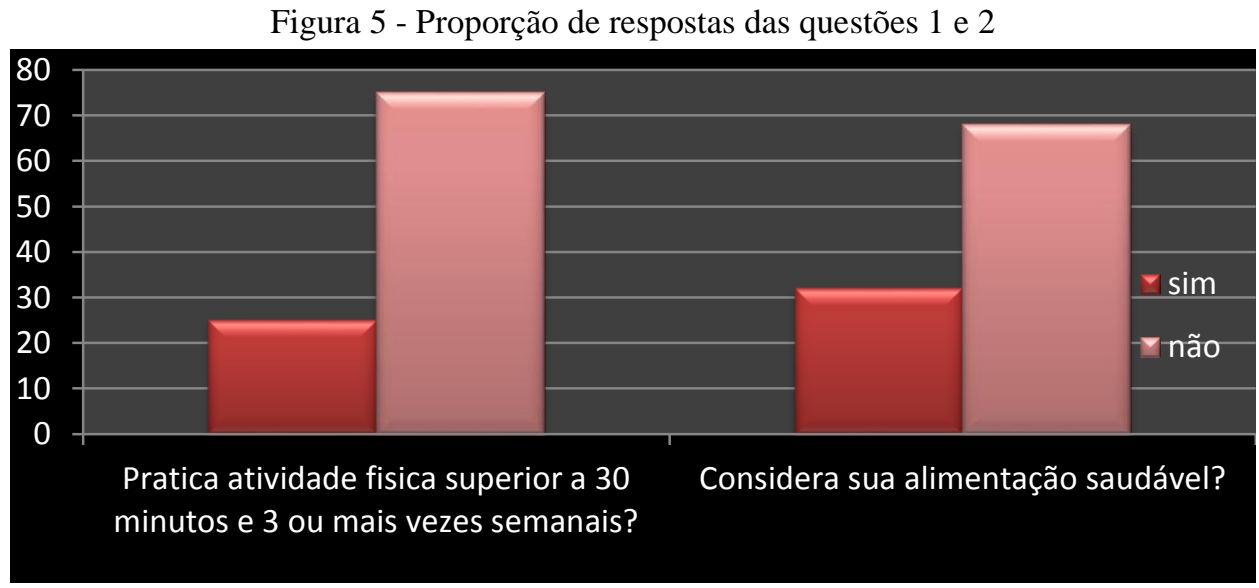

Fonte: Autores

Quando questionados sobre a frequência da ingestão de alimentos tipo fast food e alimentação com frutas e verduras, 62 alunos responderam comer com frequência alimentos do tipo fast food e 43 alunos disseram não ingerir frutas e verduras com frequência, estes dados 
estão detalhados na Figura 6. O que impulsionou ainda mais a elaboração e confecção de um jogo que envolvesse Saúde e Biologia.

Figura 6 - Proporção de respostas das questões 3 e 4

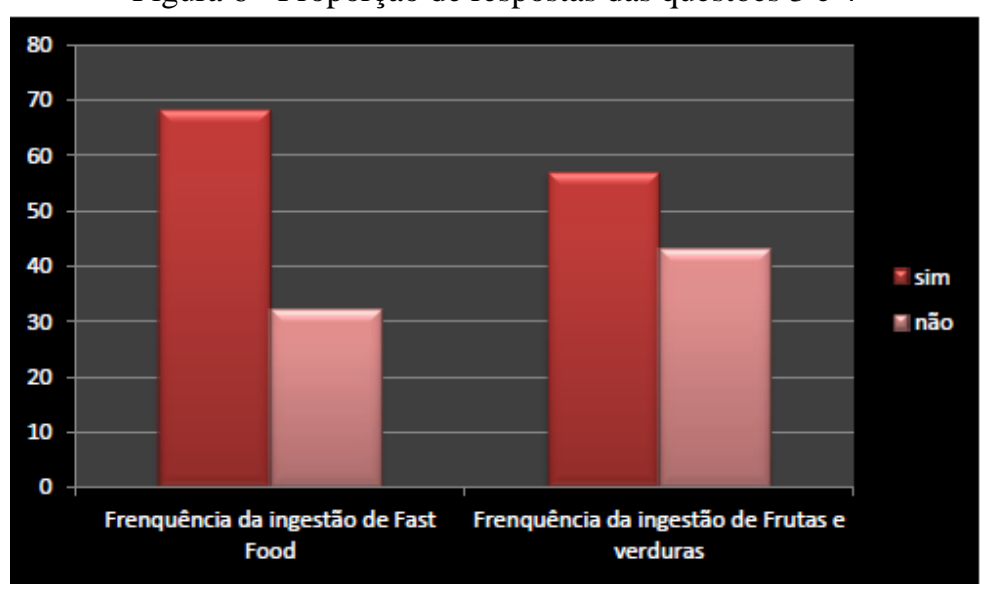

Fonte: Autores

Baseando-se nessa investigação, decidiu-se então, elaborar um jogo, no qual os alunos pudessem refletir quanto seus modos alimentares e adequar suas práticas físicas de uma maneira descontraída e que não percebessem como uma obrigação, mas como uma diversão.

Depois de projetado, o jogo foi disponibilizado para vários alunos do colégio, a fim de que muitos deles participassem de forma ativa, interagisse com a atividade e também expressassem suas considerações em relação ao jogo.

Durante a aplicação do jogo, os alunos expressaram entusiasmo e envolvimento com a atividade, principalmente em função de o instrumento ser um jogo e poder ser aplicado em grupo.

Algumas citações feitas pelos alunos que desenvolveram as atividades foram:

“- Jogar em sala de aula proporciona momentos ricos em interação entre os colegas de sala propiciando aprendizagem de uma maneira divertida e irreverente";

Os jogos, na perspectiva pedagógica, o jogo reúne um valor lúdico às situações de aprendizagem, o contexto de jogo pode envolver os jogadores em um cenário de conflito permeado de atitudes que devem ser tomadas, a partir da qual, envolvido a resolver problemas implicando na tomada de decisões.

“- Não tinha ideia da quantidade de calorias que está presente em lanche do tipo fast food";

“- Preciso repensar os alimentos da minha alimentação, são muitos calóricos. "

Moran; Masetto; Behrens (2000) apresenta como estratégia de aprendizagem, modelos de alguma situação da realidade na qual o estudante deve investigar, buscando elucidação para 
um problema, analisando as variáveis que as compõe, elaborando modelos mentais de reação a conflitos, aproximando seu cotidiano, e que o estimule a envolver-se com a atividade e a aprender para resolvê-la.

“- O bom é que as academias ao livre são gratuitas e ao lado da minha casa";

O jogo, além de prazeroso, estimulou em seus participantes diversos esquemas de conhecimentos necessários para construção de saberes cognitivos e procedimentais envolvidos com a temática do jogo, tais como, observação de fenômenos, identificação das variáveis envolvidas, reconhecimento das adversidades impostas aos casos, comparação das quantidades e das situações, localização as estruturas, além de mobilização ao raciocínio lógico, ao planejamento coerente e à tomada de decisão. Tais saberes, por meio da reflexão na ação, e reflexão da ação, também foram construídos e percebidos pelo docente ao longo da produção, aplicação e reflexão para o jogo. Schön (1995), diante da prática profissional do professor como momento de construção constante de conhecimento e que a mesma se realiza por meio da reflexão, análise e da problematização:

O processo de reflexão-na-ação [...] pode ser desenvolvido numa série de "momentos". [...] primeiramente um momento de surpresa: um professor 5 reflexivo permite-se ser surpreendido pelo aluno [...] segundo momento [...] pensa sobre aquilo que o aluno disse ou fez, e, simultaneamente, procura compreender a razão por que foi surpreendido. [...] num terceiro momento, reformula o problema suscitado pela situação [...] num quarto momento, efetua uma experiência para testar a sua nova hipótese (SHON, 1995, p. 83).

“- Preciso levar esse jogo para jogar com minha mãe”.

Não menos importante, o jogo, permitiu desenvolver habilidades atitudinais e sócio emocionais, como trabalho em equipe e cooperação, ao determinar e atender regras, superação de conflitos, autoestima, autoconfiança e favoreceu os relacionamentos interpessoais entre aluno e aluno, bem como aluno e professor.

A atividade promoveu reflexões quanto aos alimentos que os mesmos mais gostavam e perceberam o quão calórico são os alimentos, também expressaram que não faziam atividades físicas na academia ao ar livre ao lado da escola e que em grupo de colegas, passariam a frequentar mais este espaço presente na comunidade.

Para Fourez (2003) o ensino tem sentido para a compreensão do próprio mundo, percebendo razão ao observar em relato, a reflexão dos alunos diante da problemática do jogo. Schneider (2002), também discute a serventia e a contemporaneidade do que os alunos aprendem nas escolas, levam à conclusão de que os conteúdos trabalhados precisam de 
significados, de utilidade prática e, sobretudo, valorizam o desenvolvimento de habilidades. Ele enfatiza que,

\begin{abstract}
Urge buscar um modelo educacional e respectivos currículos que objetivem o equilíbrio entre valores, habilidades e conhecimentos. Se ser especialista foi condição sine qua non para vencer nas sociedades industriais, agora, com o surgimento da tecnologia da informação, com a conscientização e valorização da auto-estima do trabalhador, da globalização de mercados etc, não basta ser especialista para ganhar um lugar neste tão disputado mercado. É por essa razão que se está propondo, neste trabalho, um ambiente de aprendizagem informatizado que leve em consideração uma ergonomia cognitiva a ser alcançada pela praxi construtivista e que seja operacionalizada em uma escola que se comporte como uma organização de aprendizagem (SCHNEIDER, 2002, p. 24)
\end{abstract}

Assim, tal material pode auxiliar educadores e educandos no processo de ensino e de aprendizagem, referente aos hábitos e alimentos saudáveis. Uma vez que o conhecimento é a apropriação do objeto de conhecimento, por meio das constantes interações entre sujeito, meio e objeto de conhecimento. Santos (2003) apresenta a respeito de metodologia eficaz e a prática docente, não basta ter conhecimento é preciso inovar, buscar novas práticas para se comunicar com o aluno. Um ponto que também pode ser visto é a relação professor-aluno permeada pelo conteúdo de ensino e a forma como o professor se relaciona com sua área de conhecimento e sua percepção de ciência e de produção do conhecimento que é importante para o crescimento do aluno (NAVARRO; SILVA, 2012 apud VEIGA, 1993). Mercado (2001) expressa à necessidade de reformulação da relação professor-aluno principalmente ao se observar a relação quase igual entre os achados. De acordo com Schön (2000), os alunos aprendem fazendo, se reconhecendo na atividade, logo o docente tem o papel de mediador, por meio de um ensino prático.

\title{
5 CONSIDERAÇões FinAIS
}

Por intermédio do jogo, percebemos que seria interessante se todos os colégios incentivassem os alunos a prática de exercícios físicos, e os alertassem dos problemas de saúde ocasionados pelo sedentarismo. Proporcionar, por meio de práticas pedagógicas mais dinâmicas e atrativas, incentivando a promoção de hábitos alimentares mais saudáveis e balanceados, ricos em frutas, verduras e nutrientes essenciais ao organismo, para que possam manter o peso adequando e a manutenção da saúde. O jogo NutriBanck, foi submetido as normas da III Feira de Inovação das Ciências e Engenharias - FICIENCIAS e selecionado como finalista, evidenciando sua pertinência e relevância. 
Esse potencial se tornou real para alguns dos alunos após a realização da atividade e do feedback. Conclui-se a partir deste jogo que o brincar pode ser um riquíssimo elemento para o processo de ensino e aprendizagem, de acordo com os objetivos utilizados.

Por meio da criatividade dos alunos e da mediação do docente, se desenvolveu o processo de ensino e aprendizagem, construindo a identidade do professor, mobilizando seus saberes, de modo a reconstruir seus significados, refletindo sobre sua e para sua prática, reconhecendo na presente proposta, articulação entre a teoria de aprendizagem, aos instrumentos e objetos de estudo, assim, aliando conceitos, procedimentos e atitudes.

\section{REFERÊNCIAS}

BARDIN, Laurence. Análise de conteúdo. 70. ed. Lisboa, 2007.

BOGDAN, Robert C.; BIKLEN, Sari K. Investigação qualitativa em educação. Portugal: Porto Editora, 1994.

BATISTA Irinéa de Lourdes; SALVI Rosana Figueiredo. Perspectiva pós-moderna e interdisciplinaridade educativa: Pensamento complexo e reconciliação interrogativa. Ensaio. vol 8. $n^{\circ}$ 2. dez. 2006

DEL PRETTE, Zilda. A. P; DEL PRETTE, Almir. (1996). Habilidades sociais: uma área em desenvolvimento. Psicologia Reflexão \& Crítica, 9, 233-255.

FELIX, Fabiola Angarten; NAVARRO Elaine Cristina. HABILIDADES E COMPETÊNCIAS: NOVOS SABERES EDUCACIONAIS E A POSTURA DO PROFESSOR. Revista Interdisciplinar 2009.

FILHO, Moacyr Ribeiro do Vale. O Professor como produtor de conhecimento sobre o ensino. In. CARVALHO A. M. P. A formação do professor e a prática do ensino. São Paulo: Biblioteca Pioneira, 1987. p. 61-65.

FREIRE, João Batista. Educação de Corpo Inteiro: Teoria e Prática da Educação Física. São Paulo: Scipione, 1989.

FOUREZ, Gérard. Crise no ensino de Ciências. Investigações em Ensino de Ciências. 2003. Disponível em: https://www.if.ufrgs.br/cref/ojs/index.php/ienci/article/view/542/337. Acesso em 01 dez. 2019.

FURIÓ, Carlos; GIL-PÉREZ, Daniel. (1989). La didáctica de las ciencias en la formación inicial del profesorado: una orientación y un programa teóricamente fundamentados.

Enseñanza de la Ciencias, 7 (3), 257-65.

FURIÓ, Carlos, GIL-PÉREZ, Daniel, CARVALHO, Ana Maria Pessoa de; SALCEDO, Luis E. La formación inicial del profesorado de educación secundaria: o papel de las didácticas específicas. Investigación en la Escuela, 16, p. 7-21, 1992 
GOMES, A. C.; FILHO, N. P. de A. Croos Training: Uma abordagem metodológica. Londrina: Apef, 1992.

GUISELINI, Mauro. Aptidão Física, saúde e bem-estar: Fundamentos teóricos e exercícios práticos. São Paulo: Phorte, 2004.

MARTINS, Isabel. Alfabetização científica: metáfora e perspectiva para o ensino de ciências. In: XI Encontro de Pesquisa em Ensino em Física, 11, 2008, Curitiba. Anais XI EPEF. Curitiba, 2008

MORAN, José Manuel; MASSETO Marcos T.; BEHRENS, Marilda Aparecida. Novas tecnologias e mediação pedagógica. Campinas, SP: Papirus, 2000.

MERCADO, Luís Paulo Leopoldo. A Internet como Ambiente Auxiliar do Professor no Processo Ensino-Aprendizagem, 2001. Disponível em: http://espacio.uned.es/fez/eserv/bibliuned:1183/n03mercado02.pdf. Acesso em 07 abr. 2020.

MIRANDA, Simão de. No fascínio do jogo, a alegria de aprender. Ciência hoje. v.28, n. 168. Jan/fev. 2002, p.64-66.

MOREIRA, Marco Antônio. Pesquisa em ensino: Aspectos Metodológicos. Subsídios metodológicos para o professor pesquisador em ensino de ciências, Porto Alegre, v.1, n.1. 2009. Disponível em: http://www.if.ufrgs.br/ moreira/Subsidios10.pdf. Acesso em: 05 jun. 2017

NAVARRO Elaine Cristina; SILVA Ormenzina Garcia da. A relação professor-aluno no processo ensino-aprendizagem. Interdisciplinar: Interdisciplinar. Revista Eletrônica da Univar (2012) n. ${ }^{\circ} 8 \mathrm{Vol}-3$ p. $95-100$.

NÓVOA, Antônio. A formação contínua de professores: realidades e perspectivas. Aveiro: Universidade de Aveiro, 1991;

PÉREZ-GÓMEZ, Angel. A função e formação do professor/a no ensino para a compreensão. In: GIMENO, José Gimeno; GÓMEZ, Angel. Compreender e transformar o ensino. Tradução Ernani F. da Fonseca Rosa. 4.ed. Porto Alegre: Armet, 1998. p.353-75.

ROSSASI, Lucilei Bodanese; POLINARSKI, Celso Aparecido. Reflexões sobre metodologias para o ensino de Biologia: uma perspectiva a partir da prática docente. 2007. 25 f. (Monografia) Programa de Desenvolvimento Educacional. Unioeste, Paraná, 2007.

SANTOS, Vivaldo Paulo dos. O fazer na sala de aula: didática, metodologia ou nada disso? Unibarretos. 2003. Disponível em <https://faculdadebarretos.com.br/wpcontent/uploads/2015/11/pesquisa-sala-de-aula6.pdf.> Acesso em 18 dez. 2019.

SCHNEIDER, Henrique Nou. Um ambiente ergonômico de ensino-aprendizagem informatizado. (Tese de Doutorado), UFSC, 2002.

SCHÖN, Donald A. Formar professores como profissionais reflexivos. In: NÓVOA, A. (org.). Os professores e sua formação. Lisboa: Dom Quixote, 1995. 
SCHÖN, Donald A. Educando o Profissional Reflexivo: um novo design para o ensino e a aprendizagem. Trad. Roberto Cataldo Costa. Porto Alegre: Artmed, 2000, 256p.

STENHOUSE. Lawrence. La investigación como base de la enseñanza. Tradução Guillermo Solana. Madrid: Morata, 1987. 183p.

VYGOTSKY, Lev. A Formação Social da Mente. Martins Fontes: São Paulo, 1984.

WILLETT Walter. C.; STAMPFER Meir. J. Scientific American Brasil. Número: 9 Ano: 2003

Recebido em: 15 de janeiro de 2020.

Aprovado em: 13 de abril de 2020. 